\title{
The Discussion of Tibet’s Paintings in Dunhuang During A.D. 786-907_ And the Mural Painting on the North Side of the No.14 Cave of the Mogao Caves
}

\author{
ZHANG Ya-sha \\ Minzu University of China, Beijing, China
}

\author{
LI Nan \\ Beijing Forestry University, Beijing, China
}

\begin{abstract}
During A.D. 776 to 848, Dunhuang was occupied and ruled by Tubo political power, a special painting style, spread via the Tibetan silk road, appeared at same time, and which is related to the art style of India and Nepal; It is worth noting that the Tibetan painting style during this period have no relative unified model actually, especially the mural and the silk painting preserved in Library Cave, the painting style of which had obvious difference between each other, and the reason behind this is very hard to explain. Until the late Tang Dynasty (A.D. 848-907), sheer Pala style of eastern India appeared in Dunhuang, however, whether those East India painting style still belong to Tubo remain for further discussion. The art style of East India appeared in Dunhuang during from the late Tang Dynasty to the early period of Northern Song Dynasty, probably propagated from the ways other than Tubo, and this art style was deemed as the one has nothing to do with Tibet's art in this study.
\end{abstract}

Keywords: Tibetan painting system, silk painting, the mural painting on the west of the 25th cave of the Yulin Caves, the mural painting on the north side of the No.14 cave of the Mogao Caves

\section{Introduction}

In the summer of 1999, the investigation for the ancient painting remains related to Tubo had been made in the Mogao Caves and Yulin Cave in Dunhuang, since then two questions had been lingering in the mind: The first one is that why almost little imprint of "Tibetan type" art left in Dunhuang, although Tubo Dynasty had occupied here for nearly a century? Second, why more pure East Indian "Pala style" art, did not appeared in Tibetan regime period (A.D. 786-786), but come out in the late Tang Dynasty when the Tibetan political power has been quit out of Dunhuang (A.D. 848-907)?

In the long process of the development of Dunhuang Cave art, the style or the influence of Tibet art, mainly appeared in the two periods: first is the middle and the late Tang Dynasty (the middle or the late of 8th century to the late 9th century); second is Xixia and Yuan Dynasty (12-14 century). The first period was the one concerned by this study - the middle and the late Tang Dynasty. Comparatively speaking, in the late northern Song Dynasty, when Dunhuang ruled by Xixia political power, the "Tibetenize" phenomenon in the art here had been already

ZHANG Ya-sha, Ph.D., Professor, School of Ethnology and Sociology, Minzu University of China.

LI Nan, Postgraduate Student, College of Environmental Science and Engineering, Beijing Forestry University. 
relatively prominent, until the Yuan Dynasty, with the Tibetan Buddhism was believed in and promoted by the ruling classes, Tibetan art naturally became popular. In the Tang Dynasty, especially in the middle of the Tang Dynasty, when the politics and military of Dunhuang were all ruled by Tubo, however, the art here did not show the "Tibetenize" phenomenon, and this seems to be the contradictory points between the political power and artistic style.

\section{Tibetan Art Style of Dunhuang}

For convenience, there should be a specialized vocabulary to define the "Tibetan” painting in Dunhuang. So-called "Tibetan style" or "Tibetan art system" painting, specifically refer to the sort of the painting remains in Dunhuang, which contained the Tibetan elements or painting style, the "Tibetan style" is short for "Tibetan painting style" and the "Tibetan art system" is short for "Tibetan painting system".

When it comes to Dunhuang Tibetan art, it seems to contain all the images or things as long as the content of which related to Tubo, however, the art related to Tubo during the middle and late Tang Dynasty ought to be divided into two kinds: the first one is revealed the Tubo peoples or Tibetan political events in their content, in other words, this kind refers to the art remains with the subject related to Tubo; The second is the works drawn by "Tibetan style" artistic expression technique, namely those remains were used the Tibetan style and technique of expression to draw; Surely enough, only the second kind would be discussed in this study, the ancient works remains with the basic shape and artistic expression technique belonging to Tibetan art system.

The most essential differences between the two kinds of works remains are that they were drawn by different groups of painters and with different "tradition" of the painting technique. The former should be drawn by the local artists in Dunhuang, which just reflected the social and regime change of Tubo Dynasty, but still inherited the local style in the artistic creation techniques and artistic style, in other words, they reflected the changing time in content but no fundamental changed in form and technique. For example, the murals showing the bTsan Po bowing in front of the Buddha statue, which drawn in the No.158 and No.159 Mogao Caves, were just the one belonging to this kind. We can take a more extreme example as well, the “步劷图” drawn by Liben Yan, who is the prime minister and a famous painter in the early Tang Dynasty, this painting depicted the scene that the Emperor Taizong of Tang was receiving and meeting the envoy mGar sTong btsan Yul Srung, the subject involved here have direct relations with Tubo, but mere the content, the painter and the painted technique have nothing to do with Tubo, the painter was the prime minister in the Tang Dynasty, and the artistic style was followed the typical early traditional Chinese realistic painting pattern.

The later one, those mural paintings and silk paintings (including cloth or paper paintings) painted based on the rough sketches (with powder) stemming from Tibet (the headquarters of Tubo Dynasty) in the middle of Tang Dynasty when Dunhuang was ruled by Tubo, was believed to be the only one truly belong to the "Tibetan style" or "Tibetan art system". This kind of paintings have great differences with the traditional paintings in Dunhuang since the Tang Dynasty, except for the techniques or the styles, their blueprints were followed and based the painting style derived from India and Nepal in the South Asia during the same period, and may added some elements of the Tibetan Buddhism in the earlier stage of Tubo Dynasty as well.

It is very important and necessary to pick the "Tibetan art system" paintings out among the large number of mural paintings in the middle of the Tang Dynasty during the Tubo occupation-period, for the main art works in 
Dunhuang Caves, even in this period (786-848), still adopted the subjects and the basic techniques prevalent since the most prosperous age of Tang Dynasty, although the composition and the layout of the pictures and the contents of the “经变图” (the picture depicting the content or Buddhist sutras or the related stories) changed partly over time, the most mural paintings still maintained a consistent appearance peculiar to Dunhuang Grotto Art, and the very basic techniques with long history and profound tradition was called "Dunhuang skills of painting”, those art works with which had nothing to do with "Tibetan art system" mentioned above. That is to say, Dunhuang was ruled by Tubo in the middle of Tang Dynasty, and a lot of images related to the ruling class, appeared in Mogao Caves and other Cave groups in this period, such as the tremendous body of bTsan po, the noble providers gradually found in recent years, to indicate the political status of Tubo, however, the forms, the styles and the specific patterns of artistic presentation in this period were relatively stable and lagged behind, which indicated the continuity of the painting techniques in Central China. This phenomenon is also very hard to understand to the related researchers: why could the main mural paintings in Mogao Caves still maintained all the “Tang-style” during the Tubo occupation-period?

This phenomenon was also the first question lingered in the mind mentioned in the first paragraph in this paper, form the middle and the late of the 8th century to the middle of the 9th century, Tubo occupied Dunhuang and Hexi Corridor for nearly a century, but why the influences of "Tibetan art system" paintings could be hardly found in the mural paintings in Mogao Caves? Whether Tibetan Buddhist arts had some influences on the paintings in Dunhuang, and if there were, where they were mainly reflected in? The paper named "The mural paintings in Drathang monastery and the art in Dunhuang” was written to discuss the Tibetan art in Dunhuang in the Tang Dynasty as well (Marylin \& Thurman, 1991; Henss, 1994; ZHANG, 2001, 2006, 2008; Dagyab, 1977; Kashi Prasad Jayaswal Research Institute, Patna. 1986).

Actually, not only the number of the art remains of Dunhuang really belonging to the "Tibetan art system" in the middle and the late Tang Dynasty was very limited, but quite a part of them were very hard to identify for that they blended the "Tang-style" with the "Tibetan style" together. To be sure, however, there were several paintings belonging to "Tibetan art system" in Dunhuang during the middle Tang Dynasty and the period of time later: the number of the mural paintings was very small, the "Mandala Sutra of the Eight Bodhisattvas" paintings painted on the west wall of the No.5 of Yulin Caves, seemed to be the only one found till now which were created in the middle of Tang Dynasty; Part of the silk paintings or the paper paintings in the Caves was of the Tibetan style and elements as well.

It was very difficult to find the "Tibetan art system" painting in the mural paintings painted in the middle of Tang Dynasty in Dunhuang Caves during investigation, but it's easier to find among the silk paintings and paper paintings preserved in the Caves (with the Buddhist scriptures). Such the phenomenon appeared probably because that those silk paintings with small sizes were painted optionally and more likely and easily to be changed, the painters of which could also be the artists from any nationalities, so these silk or paper paintings, could mostly reflect the situation of cultural exchange among many nationalities in Dunhuang, contained rich and various levels of culture information, and assembled the art of all nationalities here (Han, Hu, Qiang, Tibetan people and the people from the western and central Asia), although they were merely the very small part of the whole Dunhuang art. 


\section{Types of Tibetan Paintings in Dunhuang}

Among the hundreds of paintings found in scripture-storing caves, only about dozens were the "Tibetan art system” paintings, whose materials were usually three kinds: silk, linen and paper, except for several ones with unclear data record, most of them should be the remains dating from the late of 8th century to the early stage of the 11th century.

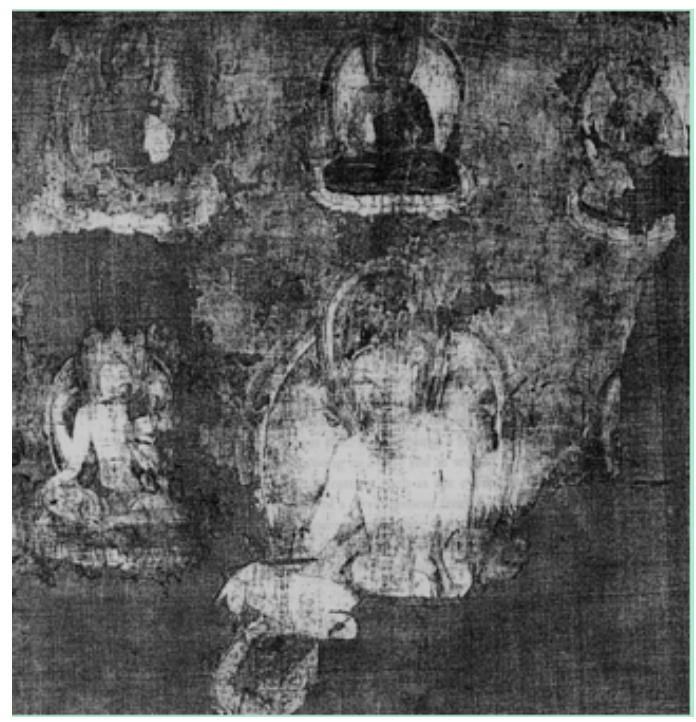

Figure 1. Bodhisattvas, the linen painting of No. 50 work of Stein's collection in the British museum.

The number of the "Tibetan art system" paintings was not so big, but they were of diverse styles, can be roughly divided into three types: the first type is the Buddha painting drawn on the linen. The representative work, the No. 50 Stein collection located in the British museum, was painted on the linen (Figure 1, Chinese traditional artist prefer to use silk to draw, but in the custom of India and Nepal, the linens were used to be the materials for painting, and this custom also had some influences on Tibetan early paintings), with the typical Indian and Nepal ancient painting patterns, small-size picture, the composition was simple and plain, some sitting Buddha or Bodhisattva lined on the paintings, with no background, and no obvious relationship between those figures. There were no significant shading of figures, but they naturally had stereo feeling. From the artistic dissemination channels prospect, this painting style should be originally prevalent in Tibet during the Tubo Dynasty, and was taken into Dunhuang by some Tibetan artists when Tubo occupied here later, and become the original copy of the “Tibetan art system” paintings.

The second type showed obvious “Tibetenize”, the No. 103 work of Stein's collection in the British museum (Figure 2) could represent this kind of works, which painted on silk or paper, usually a long strip shape picture, about $50 \mathrm{~cm}$ long and $14 \mathrm{~cm}$ wide $(50 * 14 \mathrm{~cm}$ ). The composition of the picture is very simple, only one stand Bodhisattva, except for a few Bodhisattva had a circular aura behind (seem be holy aura), most of the figures had a horseshoe or oblong aura, wearing the crown with three slender feuille jewelry, decorated with some long hairs hang down on the shoulders; upper body naked, wearing silks, sautoirs and armlets, colorful thin silk tight pants skirt under the waist; the drooped arm over the knees, with strong body and thick and straight legs, these simple and crude images could just match the grotto statues created in same period in Tibetan bdrag lha klu sgug (grotto), 
which indicated that they had obvious relationship with the "Tibetan art system" paintings (The Team of Tibetan Cultural Relics Census, 1985; HE \& Wangdue, 1985; HE, 1987).

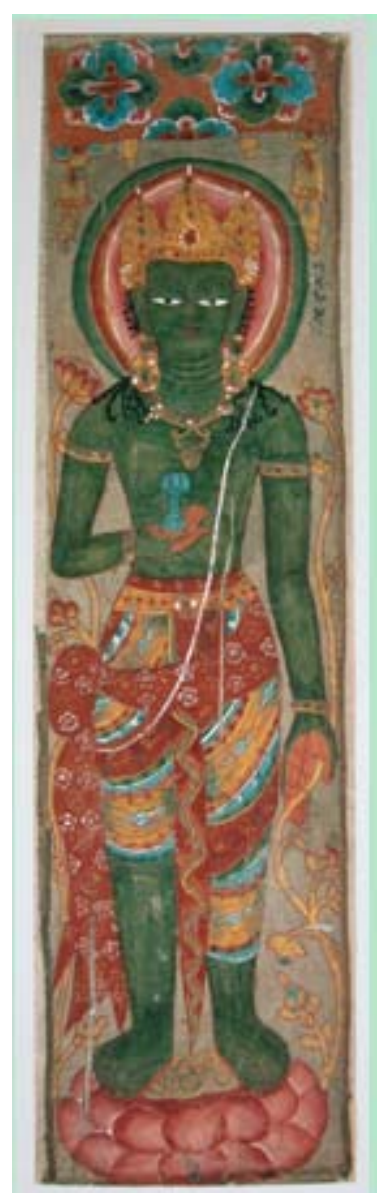

Figure 2. Vajrapani Buddhisattva, the silk painting from Dunhuang Library cave, the No. 103 work of Stein's collection in the British museum.

The third type is the one combined of the 'Tang-staly and the 'Tibetan style' together, which all painted on the silks, its representative works is the No. 32 work of Stein collections (152 cm long and $177 \mathrm{~cm}$ wide, see the (see Figure 3, Karmay, 1975), the painting consists of three parts, the top part painted the Medicine Buddha and tow Bodhidharma; The thousand-hand Bodhisattva with two Wheel Kings around (the Ruyi Wheel King is on the left hand and Huixiang Wheel king on the right) were painted on the bottom; The epigraphs of figure were written in Tibetan and Chinese in the middle of the figure; The most prominent place is that the two Buddhist painting styles (Tang-style and Tibetan style) were both adopted in same paintings. The main part of the painting showed the familiar "Tang-style", only the two Bodhisattva beside the Medicine Buddh were painted in the "Tubo-Nepal” style. Those epigraphs in figure also confirmed that the Tibetan artists dPal dbyangs indeed took part in the creation of the painting. 


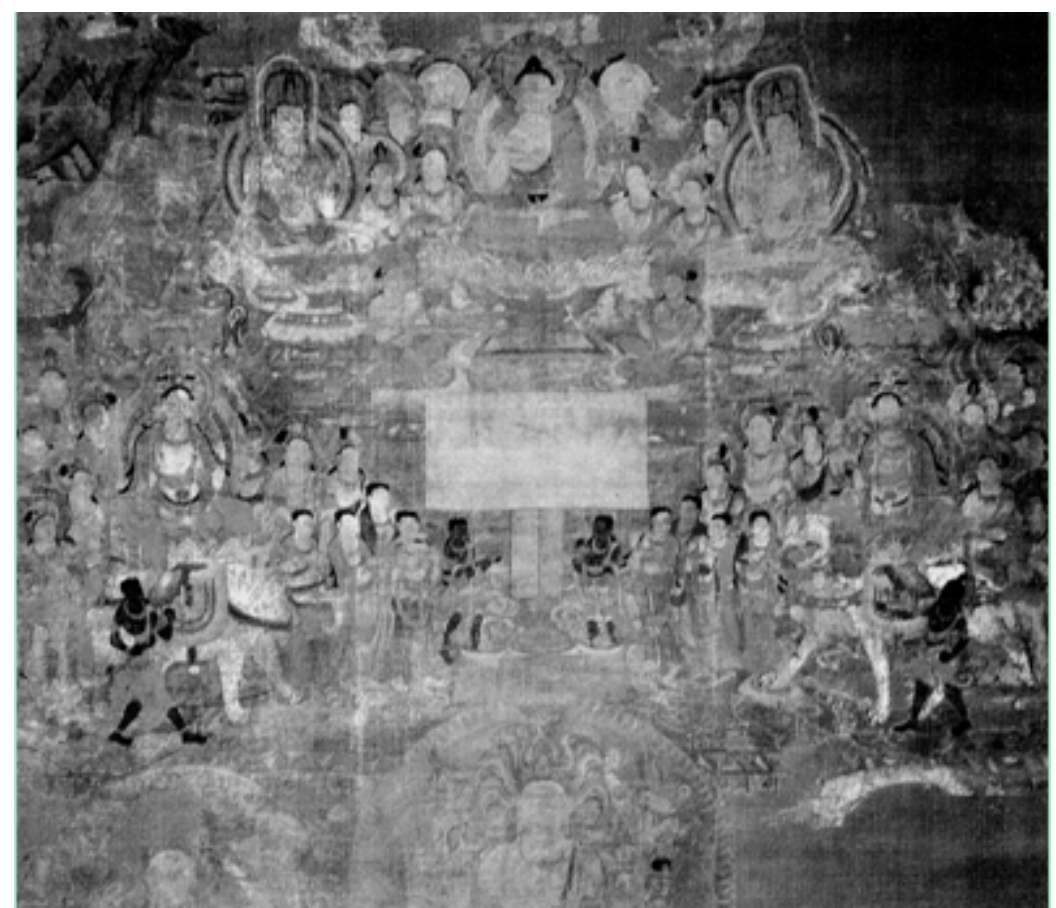

Figure 3. Medicine Buddha silk painting, the No. 32 work of Stein's collection in the British museum.

Based on the investigation, the basic characteristics of Bodhisattva images appeared in the "Tibetan art system” paintings in the middle of Tang Dynasty could be concluded as follows: (1) the Bodhisattva with 'Tubo/Nepal' style usually had oblong face with wider and sight square forehead; (2) The lower eyelids always droop, and the upper eyelids were painted as the long arcs (this drooping eyes were kept intact in later Tibetan paintings and more likely to be use as a kind of decoration); (3) A kind of barrel-shape high topknot type with cloth and silk around, was very popular in Tibet in early stage, Song bTsan sGam Po's sculptures in Jokhang temple and Potala palace, and the bTsan po images in No. 159 of Mogao grottoes all had this type of topknot, the coronets were bundled around the high barrel type topknot, the coronets were very high already, but the topknots is higher and beyond coronets, so the proportion of the topknots and coronets is rather large (often accounts for half of the whole head); (4) The aura behind the head presented horseshoe-shape or oblong shape, the design of the aura behind the back and the head is very simple, with no decorative pattern, only a few color ribbons; (5) The arm hanging down of the vertical Bodhisattva was always too long and the fingers part has already reach the knee. 


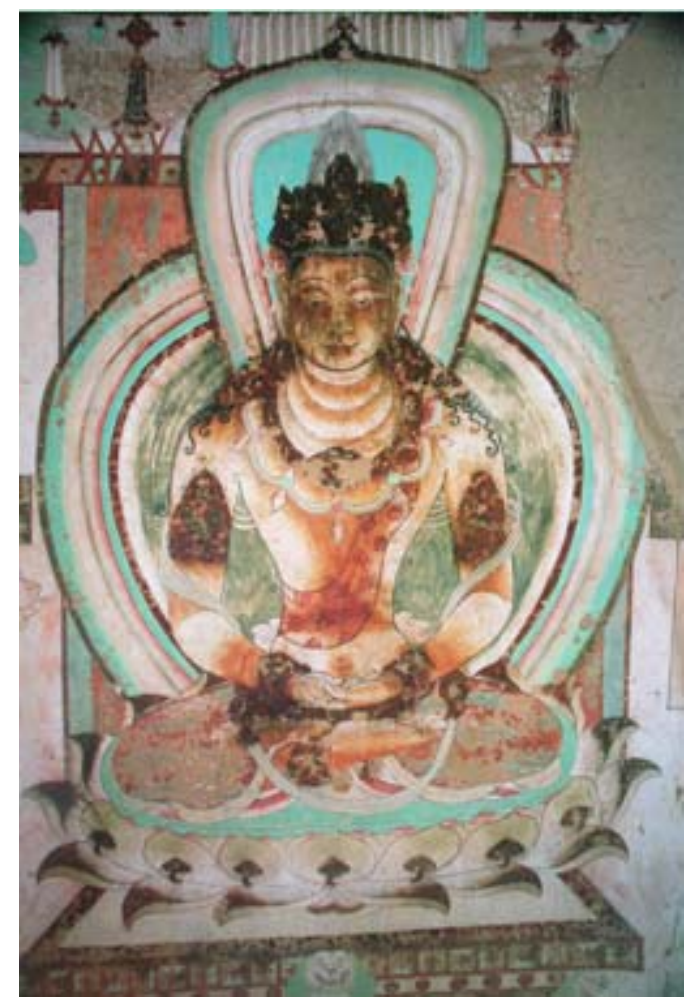

Figure 4. Vairocana, the main image in the painting of the Mandala Sutra of the Eight Bodhisattvas.

It is worth noting that the "Tibetan style" could be seen clearly in the "Mandala Sutra of the Eight Bodhisattvas" painted on the west wall of the No. 25 Yulin Caves (see Figure 4), because this group of paintings have clear and concise evidence on the age of creation, and which is very helpful to dating these "Tibetan style" paintings preserved in the Library Caves. As we know, it is hard to estimate the date of the paintings in the Library Caves, especially those remains without clear records, the only thing can be sure was that they're painted at least before the 11th century, but it was very difficult to identify the specific date of each work.

The evidence on the date of the "Mandala Sutra of the Eight Bodhisattvas" painting were listed as follow: (1) This Mandala paintings or sculptures, namely, of eight great Bodhidharmas were the classical subjects prevalent in Tibet, especially the "great Tibet" (the regions occupied by Tubo armed forces after the middle of 8th century) during the Tubo Dynasty, such as the stone Inscription groups made in the early stage of the 9th century preserved in Changdu and Yushu, almost all adopted the mandala of eight big Bodhidharmas as their subjects (Heller, 1994, 1997); (2) A pair of white lions with green hairs could be found under the lotus thrones of all the eight great Bodhidharma and the Rulai Bodhisattva in the middle, the similar images could be found on the statues in Wencheng temple located in Yushu, Qingha province, which had been made by craftsmen in AD 806 (Chab sbel tshe brdan pen tshogs, 1988; TANG, 1998), based on this, the date of "Mandala Sutra of the Eight Bodhisattvas" painting can be estimated as well; (3) The date estimation of this paintings was based largely on the themes and styles of Chinese Buddhism in the caves, and the Dunhuang academy rated that they were painted in the late 8th century (DUAN, 1987); (4) The style of the "Mandala Sutra of the Eight Bodhisattvas" paintings is very different from other three mural paintings in the same cave, and is the typical "India/Nepal" style, but in 
terms of overall style, it is relatively simple, different form the gorgeous India Pala style after the 10th century, which indicate that and the style of this painting should belong to the early east India Pala style (8-9 century).

\section{Reform, Innovation and Change}

To sum up, the "Tibetan art system” paintings remains dating in the middle of Tang Dynasty could be divided into two kinds: one is the mural painting and another one is the silk or paper painting with small amount found in the Library Caves in 1900. The "Mandala Sutra of the Eight Bodhisattvas" wall painting with clear date was chosen to be the reference for those silk paintings with unclear date records, through the comparison, it could be found that the two kinds of remains ought to follow the same artistic model, but still had some differences on the detail artistic processing.

Two conclusions could be drawn then:

(1) A "foreign" painting model indeed appeared since Dunhuang was occupied by Tubo, which was more likely to be derived directly from the Esoteric Buddhism of India/Nepal, and had influence on all the mural and silk paintings related to Tibetan folk activities in Dunhuang in the middle of Tang Dynasty. This model, however, had the most direct and powerful influence on the mural paintings, so that the image of the figures and the painting style of the "Mandala Sutra of the Eight Bodhisattvas" painting were totally different from the two other "Sutras figures" with "Tang-style" painted on the north and south side of the walls within the same cave in the same period, and which provided the most powerful evidence for the "Tibetan art system" painting preserved in the middle of the Tang Dynasty, althiygh it is indeed a very isolated case.

(2) Comparing with the almost only mural painting remains, the silk paintings preserved in the Library Caves with the number of the advantages, but had more complex situations. According to the three types of the silk paintings mentioned above, it could be found that the pure "India/Nepal" style could hardly been found among those silk paintings related to the "Tibetan art system" art, and most of the remains showed the "modification marks" in different degrees.

The "modification" in art activities, actually belong to a kind of innovation, or the local artists adding their own understandings intentionally or not when they were adopting a foreign artistic model. The variation of the artistic pattern or style during the Tibetan art history, which can be regarded as one of the features of the Tibetan art (based on my experience and many years research), was mainly caused by those "modifications" and "combination" in artistic creation. And Dunhuang should be paid special attention to, for that the "Tang-style" and the "Tibetan style" would be more likely to communicate with and absorb each other in this region. This is why that it was very difficult to find a relatively uniform style of those “Tibetan art system” paintings, preserved in the Library Caves, although the number of which was not so much. 


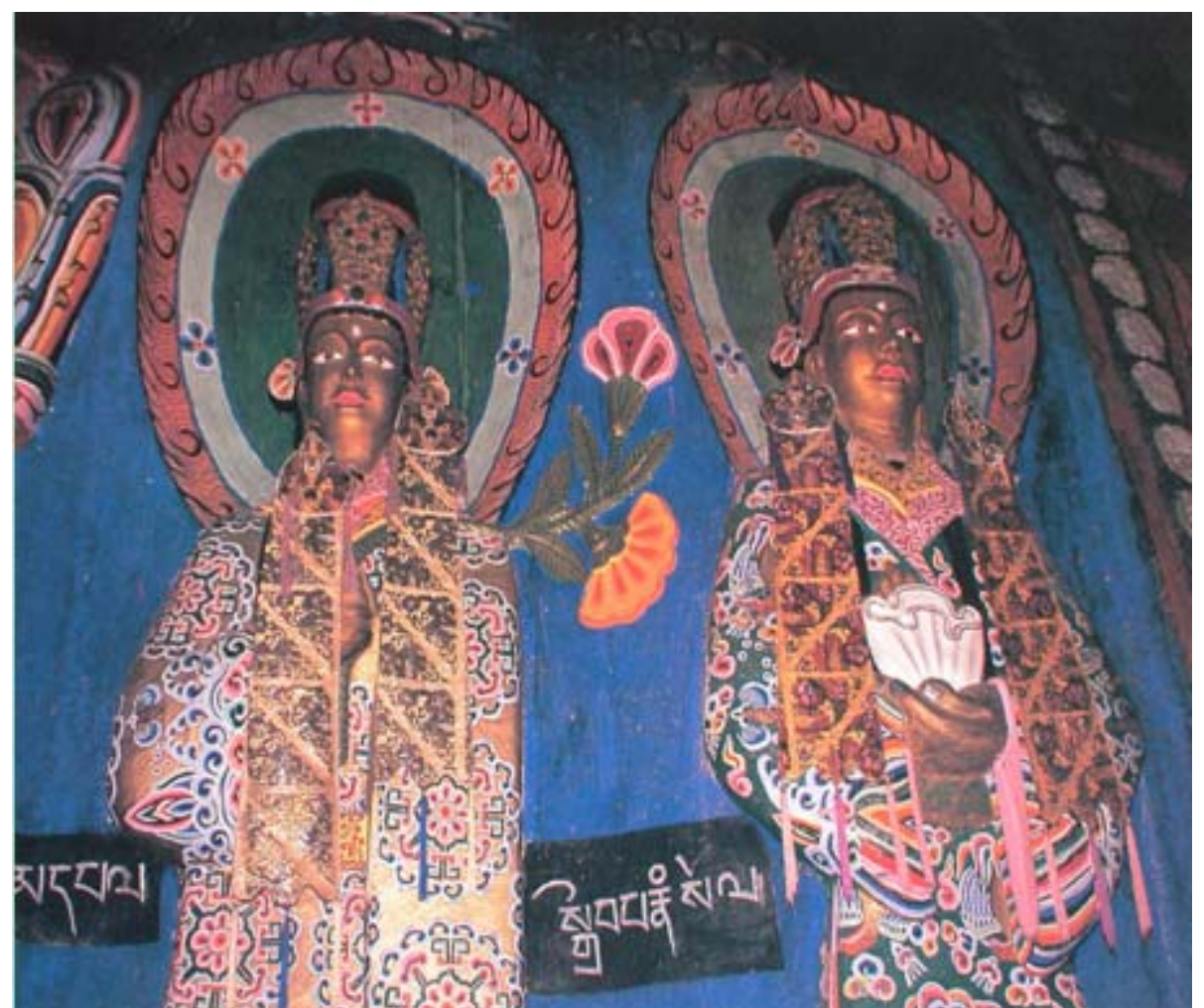

Figure. 5. Two bodies of the Mandala Sutra of the Eight Bodhisattvas, A.D. 806, basso-relievo in Wencheng temple, Yushu, Qinghai provice.

Presumably because the "Tang-style" and the "Tibetan style" had been communication for all the time in Dunhuang, the "mutability/changeable" became one of the prominent feature of "Tibetan art system" paintings and the early Tibetan Buddhism art style (those changing had been not slow down until the Qing Dynasty, when the basic style and model were formed). Actually the 'mutability/changeable' would be found in the history of all kinds of art, but it was not common that such strong sense of "changeable" in the development of the early Tibetan art, which may be caused by the several reasons as follows: Firstly, early (8th-12th centuries) Tibetan art had always been in state of active learning, innovation and creation; Secondly, the artists in that period, on the one hand, all painted strictly according to the Sutra of Measurements for The Construction of Statues, on the other hand, however, seemed to prefer to add some own innovations in the some places where it doesn't matter, such situation seems to be more obvious during the Tubo-occupation period, and continued into the middle of the Song Dynasty. Until the transition from the Song and Yuan Dynasty, a fixed pattern of Tibetan Thangka formed basically, and once the main pattern formed, a few details were the only part that may be changed later. Moreover, perhaps Dunhuang was only a peripheral area to Tubo Dynasty to control and ruled, and had independent culture, so the Tibetan artists here seems to be more active in innovation, and the real innovation or larger changes, actually all occurred in those peripheral areas such as the central and west Tibet (dwus gTsang and mgNae res), namely the Tubo occupied area in the middle of Tang Dynasty. For instance, 'the Mandala Sutra of the Eight Bodhisattvas' stone statues, located in the Wencheng Princess Temple built in the early stage of 9th century in Yushu, in Qinghai province, were modified and revised to the Indian Buddha and Bodhisattva wearing the 
clothes of bTsan po (see Figure 5), similar situations were more likely to be found in the areas such as the Amdo and Khampa according to current archaeological discoveries, where were the edge of Tibetan empire.

\section{Mural Painting in N0. 14 Cave of Mogao in Late Tang}

There are two mural paintings with obvious Eastern Indian Pala style in the middle and the late of Tang Dynasty: one is the "Mandala Sutra of the Eight Bodhisattvas" wall painting in the No. 25 Cave in Yulin (A.D. 776-848) mentioned above, another one is the "Avalokitesvara" wall painting (see Figure 6) on the north wall of the No. 14 Mogao Cave painted in the late of Tang Dynasty (A.D. 848-906, the Guiyijun period after the Tubo regime dropped out from Dunhuang and Hexi Corridor). The images, positions, the cloth, the wearing and the color schemes of the figures in two paintings all showed the clear Pala style, however, comparing the two works, the different features of the age showed and the different artistic tastes reflected between each other, seemed to be more than the common places in their form.

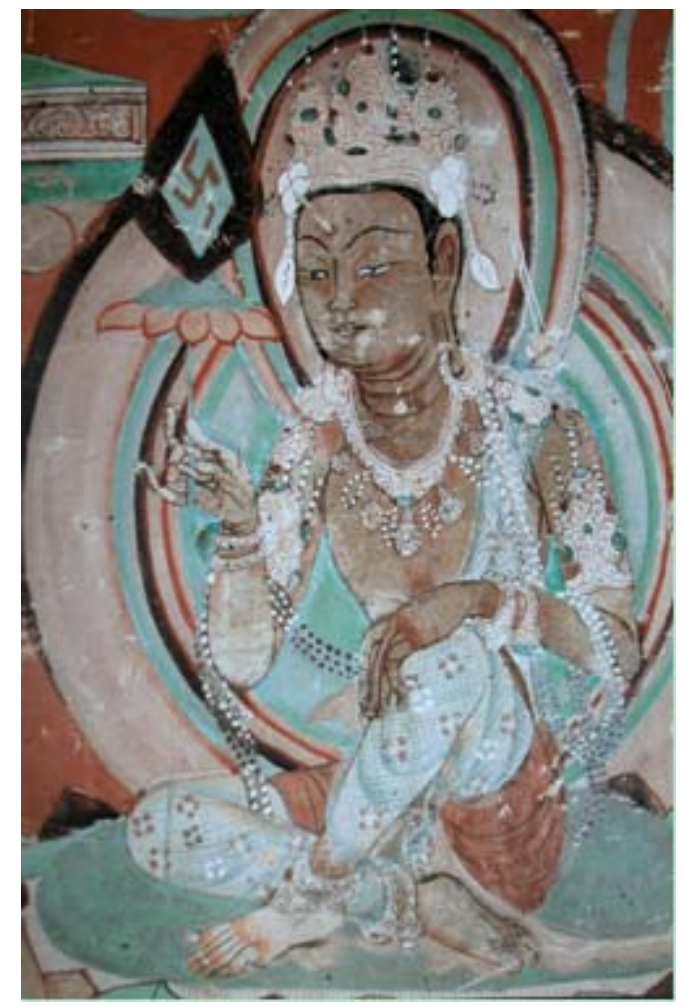

Figure 6. Avalokitesvara painting in No. 14 cave in the Mogao Grottoes.

In comparison, the painting in Yulin, on the whole, was of steady and heavy color, plain and simple shape and flatter the brushwork of Dunhuang (see Figure 3); while the "Avalokitesvara” painting in Mogao grottoes, showed the poignant and blurred atmosphere peculiar to the late of Tang Dynasty, more adopted mineral green, and overall was of very elegant and unsophisticated tone (see Figure 6). Although the two paintings were both influenced by the Pala style blueprint significantly, they still have quite different artistic atmosphere: the former was simple but heavy, the latter was gorgeous but aura, these differences suggested not only the their different ages, but also the different propagation paths. The art of the Pala style in the early stage (A.D. 8th-9th century) 
was of the heavy style, the later the stage was (after 10th century), the more gorgeous and elaborate showed in which.

However, it was perplexing to find more obvious Pala style in the latter paintings painted in the late of Tang Dynasty, which was also the second questions appeared in the mind since 1999 mentioned in the first paragraph. It was obviously contrary to the basic logic of the development of the art history, for that such pure "Pala style" painting more directly connected to Tibetan culture and art, could appeared in Dunhuang when the Tubo regime dropped out from Dunhuang and back to the central Tibet. Of course, it was undeniable that there may be a large number of Tibetan people including Tibetan artists still stayed in the local and they may produced some art works here after the Tubo regime and military forces withdrew from the Hexi corridor. But actually, it could not be find that the art works found in the late of Tang Dynasty was follow the Tibetan styles handed down from the middle of the Tang Dynasty, so the painting in Yulin cave mentioned before was the only one case remained so far. What's more, even if those left artists could still engaged in Buddhist painting creation activity, which should belong to folk activity apparently be more close to and the paper or the silk paintings in the Library Caves.

Based on this, the relationship between the "Avalokitesvara" painting in Mogao grottoes and the eastern India Pala art, were more likely to be explained in another way. This painting was used to belong to the "Tibetan art system" paintings, but now which may be dubious and remain to explore based on the research on the Tibetan art history during the Song Dynasty over the years. Those painting remains with clear east India Pala style or factors were regarded to belonged to "Tibetan art system" art, because that the Pala style could appeared in Dunhuang in the middle of Tang Dynasty, which indeed was the result of the Tibetan occupation. The Buddhist culture prevalent in Tubo Dynasty was mainly derived from the India in the south, after Tubo had occupied Dunhuang, Tibetan Buddhist culture was developed here and the early Indian/Nepal's painting style was brought in from the Tibetan plateau at the same time (in the middle of Tang Dynasty). So as long as the India/Nepal style appeared in the paintings in Dunhuang, which would be included in the 'Tibetan art system' paintings, just like the painting painted in the late Tang in Mogao Caves. However, with more in-depth and detailed analysis, the problems would be found in the following aspects:

(1) The blueprint, which the mural paintings in the No. 14 Mogao Cave were painted based on, was absolutely derived from India, but it is quite doubtful that it was brought in through the silk road along the Tibetan plateau in the late of Tang Dynasty. Actually, the similar style was never found at least in the central Tibetan region the entire Tibetan plateau, during the middle of the 9th century to 10th century and even late. More importantly, after the collapse of Tubo Dynasty, it was a question that whether there was still the relationship between the central Tibet and Dunhuang, and those Tibetan people left in Dunhuang would be no longer the leading actors here, and was not possible to gain the continuously supports from central Tibet and the Indian/Nepal, especially to get such local or pure painting blueprint.(HE, 1986; SU, 1996.)

(2) This “Avalokitesvara” painting painted based on Buddhist texts is the Avalokitesvara's sutra of mandala, this sutra was prevalent in Dunhuang, but had noting to do with the "Tibetan art system" in the late Tang Dynasty, which was very different from the case of the paintings in Yulin, which was just painted based on the "mandala sutra of eight great Bodhidharmas”, the most popular one in Tubo empire in the late of Tubo Dynasty.

(3) The ideas and details of these mural paintings in Mogao cave are very faithful to blueprint, and that's why they will give us a strong impression, however, this kind of pure Pala style paintings without so much 
"changes”, was quite different from the "Tibetan art system" art with the vary "changeable” feature mentioned above.

(4) The purpose and the function behind the two mural paintings were different. The wall painting of No. 25 Yulin cave clearly emphasized the orthodoxy and the dignity of the Tibetan Buddhist in middle of the cave (implied the dominant position of Tubo Dynasty): the Mandala Sutra of the Eight Bodhisattvas were located on the center of the wall, with the inherent Dunhuang Bodhidharma on the sides, the images itself also looked very solemn (seems to conveys the special status of the Tibetan art); the No. 14 mural paintings in the late of Tang Dynasty, however, looked gentle and relaxed, in other words, there were no special implications behind this group of paintings.

(5) One thing should be noted, that the two groups of murals paintings were both in the caves with contemporary Chinese Dunhuang paintings, that is to say, the whole environment of the mural paintings should be taken into account in the research on them. It should be noted that the "Mandala Sutra of the Eight Bodhisattvas" paintings and mural paintings on the both sides of the caves, definitely belong to two painting patterns (Tang-style and Tibetan style), such big differences between them were not only on the modeling concepts, the basic color arrangement, but also the sutra they based on, in general, the differences could be definitely found at a glance. The two mural paintings on the two walls in Mogao grottoes, however, should be as a whole, for that the sutra they were based on and the contents they painted actually were one group, the difference was only a matter of technology. The differences between them may be hardly found at first glance, and their different images and shapes of the figures and the art styles could be discovered in the further detailed observation (indicated that the blueprint they were followed were different). It is interesting to note that, without carefully observation, the differences on the color arrangement and the integral atmosphere between them could hardly be found, that is to say, although the basic shape of the figures were different, but there were no big differences on the expression techniques. These facts indicated that: the two paintings with two styles (Tang-style and Tibetan style) in No. 25 Cave in Yulin ought to be painted by the artists of Han people and the Tibetan artists respectively, but the two paintings, with different style, in No. 14 Mogao Cave, were drawn by the same or one group of artists, and differences on the style between them were merely due to that they were painted according to different blueprints.

(6) The location of the two groups of mural paintings should be also paid special attention, for that the mural paintings related to 'Tibetan art system' art, no matter the early ones (painted in the middle and late Tang Dynasty) or the late ones (painted in Xixia and Yuan Dynasty), were all mainly concentrated in the regions other than the south of Mogao grottoe, the early ones were mainly concentrated in Yulin Caves, the eastern and the western thousand-buddha Caves, the late ones had occupied the Mogao Cave, but mainly in the north, rather than the traditional southern district. So the No.14 Cave located in the southern district, and painted in the late Tang Dynasty, it seemed to indicate that the paintings in the cave had no deep or direct relationship with the 'Tibetan art system’ paintings. 


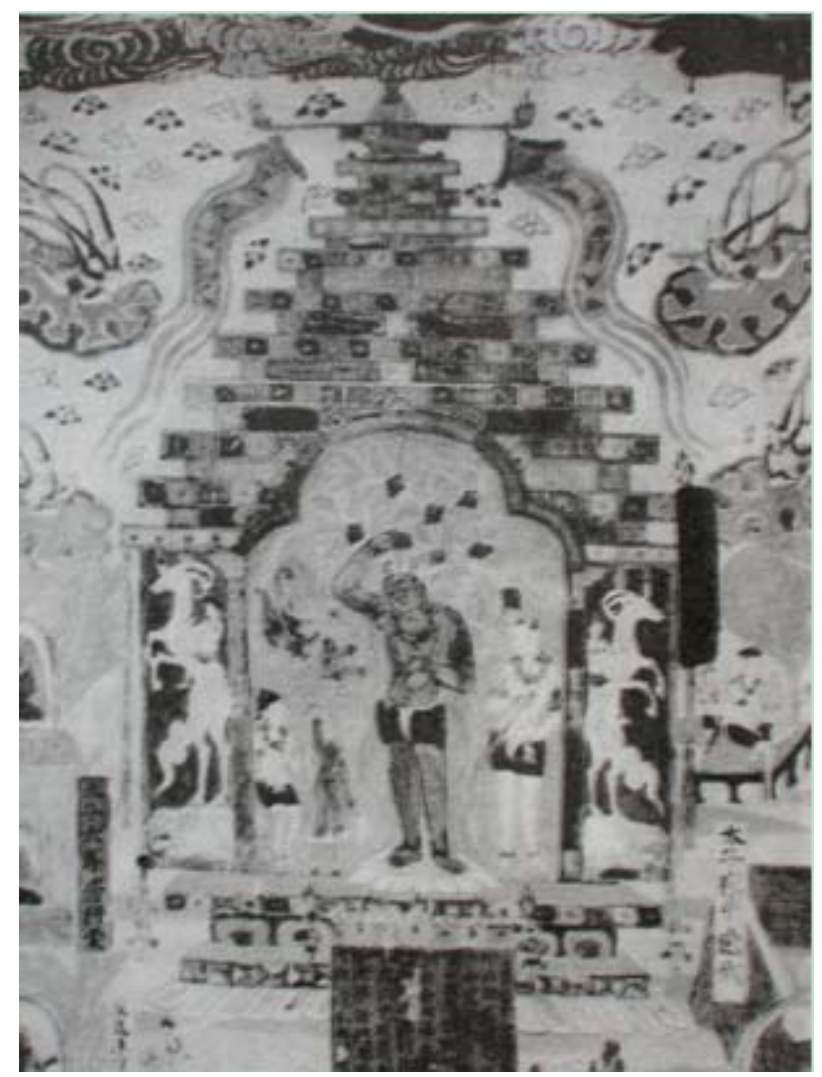

Figure 7. The mural painting in the No. 76 cave in the Mogao caves in the early Northern Song Dynasty.

(7) Perhaps the more important evidence was the mural paintings with very pure Pala style painted in the No. 76 of Mogao cave in the early years of the Northern Song Dynasty (see Figure 7), these typical east Indian Pala type pagoda images should be the earliest cases appeared in China, and these pagodas had very profound influence on the Tibetan Buddhism in later 11th-13th century. The emergence of these pure Pala style indicated that these Pala style art, actually, had been brought in Dunhuang through some certain channels, during the late of Tang Dynasty to the early of Northern Song Dynasty, at least, they ought to not mainly be brought in through Tibet during this period.

Then the conclusions could be drawn as: “ the Mandala Sutra of the Eight Bodhisattvas” painting painted in the middle of Tang Dynasty in Yulin Cave and the "Avalokitesvara” painting painted in the late of Tang Dynasty in Mogao Cave, the two groups of paintings were all followed the eastern Indian Pala style, but could not be all regarded as the ones These mural paintings were more likely to follow the blueprint derived from the same region but different ages, and were painted by the artists from different ethnic groups and for different purposes.

\section{Conclusion}

In Dunhuang, a big melting pot for the multi-ethnic art and cultural exchange and integration, “Tibetan style” paintings didn't dominant in number, but their artistic appearance were quite unique, and were of great significance in cross-cultural communication. In terms of the cultural history, the art in the Dunhuang, in west of China, with the Tibetan Buddhist art joined in, was more colorful obviously, its cultural diversity and historical thickness increased as well; From the perspective of the art archaeology, because the ancient paintings of Tubo 
Dynasty preserved in the central Tibetan regions were very rare, so those painting remains preserved in Dunhuang become very precious data of the early Tibetan art history, which were of great significance on the reduction of art history of Tubo period and the searching for the trace of art communication between the Tibet and the Central Plain in the Tang Dynasty. So it can be seen that the research on the painting remains of Tubo Dynasty in Dunhuang, is very important, not only for the abundance of the Dunhuang studies, but also for the Tibetologic studies.

\section{References}

Chab sbel tshe brdan pen tshogs. (1988). Analysis of the Newly Discovered Cliff Gxplorer of Tubo Dynasty. China Tibetology, (1), 78-80.

Dagyab, L. S. (1977). Tibetan Religious Art (Vols.XI) (pp.25-35) (J. S. XIE, Trans.). Lhasa: Tibetan People’s Publishing House.

DUAN, W. J. (1987). Mural art of Yulin Cave. Yulin Cave of Anxi (pp.163-165). Beijing: Cultural Relics Publishing House.

HE, S. Z. (1986). The mural paintings of Mogao Caves in the earlier Song Dynasty (960-1127). Mural Art of Mogao Caves of Earlier Song Dynasty (pp. 2-3). Lanzhou: Gansu People’s Publishing House.

HE, Z. D. (1987). First exploration of bdrag lha klu sgug (Grotto). Tibetan Studies, Lhasa, 1987(3), 35.

HE, Z. D., \& Wangdue, S. (1985). Elementary introduction of the cliff statues in Yaowang mountain, Lhasa. Tibetan Studies, Lhasa, (4), 113-115.

Heller, A. (1994). Early ninth century images of Vairochana from eastern Tibet. Orientations, 25(6), 74-78.

Heller, A. (1997). The cult of vairochana in Tibet/750-1200A.D./According to Tibetan Rituals from Dunhuang Manuscripts and Artistic Representation. 1997 Beijing International Symposium Papers Collection. Beijing: Publishing House of China Tibetology.

Henss, M. (1994). A unique treasure of early Tibetan art: The eleventh century wall paintings of Drathang Gonpa. Orientation, 25(6).

Karmay, H. (1975). Early Sino-Tibetan art (pp. 17-25). Warminster, England: Aris and Phillips Ltd..

Kashi Prasad Jayaswal Research Institute, Patna. (1986). The Album of the Tibetan Art Collections. Collected by Pt. Rahula Sankrityayana from the Nor, Zhalu and other monasteries in 1928-29 and 1934.

Rhie, M. M., \& Thurman, R. A. F. (1991). Wisdom and compassion: The sacred art of Tibet. New York: Tibet House New York in Association with Harry N. Abrams, Inc..

SU, B. (1996). The Tibetan religious relics in the two caves of Yulin and Mogao. Engage in Archaeological Studies of Tibetan Buddhist. Beijing: Cultural Relics Publishing House.

TANG, H. S. (1998). Research of the Buddhist Cliff on Yushu, Qinghai in Tang Dynasty. China Tibetology, (1), 114-116.

The Team of Tibetan Cultural Relics Census. (1985). Brief Report of Investigation about bdrag lha klu sgug (Grotto). Journal of Cultural Relics, Beijing, (9), 51-61.

ZHANG, Y. S. (2001). The wall paintings of Drathang Monastery and Dunhuang art. China Tebitology, (3), 92-95.

ZHANG, Y. S. (2003). A study of the sculptures of Iwang Temple and an analysis of the their art style. China Tebitology, (2), 80-90.

ZHANG, Y. S. (2006). The art history of Tibet (pp. 150-152). Beijing: Publishing house of Minzu University of China.

ZHANG, Y. S. (2008). Tibetan Buddhist art in 11th century: From the study of the Mural Paintings in Drathang Monastery (pp. 210-218). Beijing: Publishing House of China Tibetoloty.

ZHANG, Y. S. (2015). Evolution of early style of Thangka in central Tibet. 2015' collection of BBS Thangka Beijing China (pp. 144-151). Beijing: Cultural Relics Publishing House.

ZHANG, Y. S. (2016). The art of Tibet during Song Dynasty. General history of Tibet (Vol. 8, Chapter 11) (pp.432-440). Beijing: Publishing House of China Tibetoloty. 